\title{
Fatores interferentes da qualidade do sangue de cordão umbilical/placentário para transplante autólogo: revisão integrativa
}

\section{Interfering factors of blood quality of the umbilical cord/placentary for autologous transplantation: integrative review}

\author{
Luísa Perissé' • Paula de Araújo Nicolini Rosa ${ }^{2} \bullet$ Cristiano Bertolossi Marta ${ }^{3}$ Elzeni dos Santos Braga ${ }^{4}$
}

\begin{abstract}
RESUMO
Esse estudo tem como objeto os fatores que podem influenciar na qualidade do SCUP e como objetivo apontá-los e defini -los, seguidos da análise de boas práticas na coleta de SCUP, sintetizando, em seguida, informações acerca de boas práticas de coleta. Metodologia:Trata-se de uma revisão integrativa, norteada pela metodologia PICO. As buscas foram realizadas no Portal da BVS e foram selecionados 15 artigos que abordam a temática. Resultados: Os autores apontam para a associação entre o maior volume de SCUP coletado e o maior número de células nucleadas totais obtidas. O volume da coleta pode ser influenciado pelo peso da placenta, via de parto, tamanho do cordão umbilical, peso e idade gestacional do RN, e também está associado a fatores operacionais, como manuseio incorreto da placenta e cordão umbilical. O número de células nucleadas totais também está associado ao intervalo entre coleta e processamento, via de parto e à temperatura de armazenamento durante o transporte. Conclusão: Para obter-se uma coleta de qualidade, deve-se coletar o maior volume possível, reduzir o intervalo entre coleta e processamento e observar as boas práticas de coleta. $\mathrm{O}$ aperfeiçoamento da técnica de coleta pode ser obtido através de um programa de capacitação contínua dos coletadores.
\end{abstract}

Descritores: sangue de cordão umbilical, protocolo clínico, coletadores, qualidade

\begin{abstract}
This study has as object the factors that can influence the quality of the SCUP and aim to identify and define them, followed by the analysis of good practices in the collection of SCUP, then synthesizing information about good practices of collection. Methodology: This is an integrative review, guided by the PICO methodology. The searches were carried out in the VHL Portal and 15 articles were selected that address the subject. Results: The authors point to the association between the highest volume of SCUP collected and the highest number of total nucleated cells obtained. The volume of the collection can be influenced by the weight of the placenta, tract of delivery, umbilical cord size, weight and gestational age of the newborn, and is also associated with operational factors such as incorrect placenta and umbilical cord management. The number of total nucleated cells is also associated with the interval between collection and processing, delivery route and storage temperature during transport. Conclusion: In order to obtain a quality collection, one must collect as much volume as possible, interval between collection and processing and observing good collection practices. The improvement of the collection technique can be obtained through a continuous training program of the collectors.
\end{abstract}

Descriptors: umbilical cord blood, clinical protocol, collectors, quality

'Especialista em Enfermagem do Trabalho pela Universidade Federal do Rio de Janeiro (2013), Especialista Clínica Médica e Cirúrgica nos Moldes de Residência pela Universidade Federal do Estado do Rio de Janeiro (2015), Especialista em Neonatologia pela Universidade Veiga de Almeida. Email: Luisa.perisse@outlook.com ${ }^{2}$ Especialista em Enfermagem Neonatal pela Universidade Estadual do Rio de Janeiro (2005). Atua no Instituto Fernandes Figueira como Enfermeira Coordenadora da Enfermaria de Cirurgia Pediátrica. Também é professora colaboradora dos cursos de especialização e residência em enfermagem pediátrica e em enfermagem neonatal. Email: Paulinhal80@gmail.com

${ }^{3}$ Mestrado em Enfermagem pela Universidade do Estado do Rio de Janeiro (2005), Doutorado em Enfermagem pela Escola de Enfermagem Anna Nery da Universidade Federal do Rio de Janeiro (EEAN/UFRJ) e Pósdoutorado pela Escola de Enfermagem Aurora Afonso Costa da Universidade Federal Fluminense (EEAACl UFF). Avaliador do Sistema Nacional de Avaliação da Educação Superior do Instituto Nacional de Estudos e Pesquisas Educacionais Anísio Teixeira (Inep/BASis). Professor Adjunto e coordenador da sub-área de Administração em Enfermagem do Departamento de Fundamentos de Enfermagem da Faculdade de Enfermagem da Universidade do Estado do Rio de Janeiro (DFEN/FENF/UERJ) atuando como docente preceptor do Estágio Supervisionado na modalidade de Internato em Enfermagem e docente responsável pela disciplina Suporte Assistencial de Enfermagem na Residência em Enfermagem. Membro do Laboratório de Avaliação Econômica e de Tecnologias em Saúde (LAETS) da Escola de Enfermagem Alfredo Pinto da Universidade Federal do Estado do Rio de Janeiro (EEAP/UNIRIO); Coordenador do Núcleo de PósGraduação em Enfermagem e Diretor do Núcleo de Pesquisa da Universidade Veiga de Almeida. Pesquisador Líder do Núcleo de Avaliação de Tecnologias e Economia em Saúde e Segurança do Paciente (NATESSP) da Universidade Veiga de Almeida. Email: Cristianobertol20I4@gmail.com ${ }^{4}$ Mestre pela EEAN/UFRJ. Especialista em Gestão Hospitalar pelo HSL/FIOCRUZ. Especialista em pediatria pela EEAN/UFRJ. Especialista em cardiologia pela EEAP/ UNIRIO/INC/MS nos moldes de residência.Atualmente é Enfermeira Gestora da UTIN Cirúrgica da Fundação Oswaldo Cruz / IFF. Email: Elzenibraga@yahoo.com.br 


\section{INTRODUÇÃO}

Células-tronco embrionárias (ES) têm o potencial de proliferar indefinidamente em cultura e podem se diferenciar em qualquer tipo de célula ${ }^{(1)}$. As mesmas são capazes de promover a reconstituição hematopoiética e de outros tecidos, estando presentes no sangue periférico, medula óssea ${ }^{(2)}$, parênquima hepático embrionário ${ }^{(3)} \mathrm{e}$ sangue do cordão umbilical(4).

Em 1988, estudos realizados com amostras humanas ${ }^{(5,6)}$ evidenciaram que o Sangue de Cordão Umbilical e Placentário (SCUP) possui maior proporção de células produtoras de colônias imaturas e progenitoras de eritrócitos primitivas, quando comparado à Medula óssea, por exemplo. Iniciou-se, entãoa aplicação deste produto em terapias com finalidade de restabelecer a função das células estaminais hematopoiéticas em pacientes acometidos por neoplasias malignas e outros distúrbios.

Além disso, outros estudos vêm sendo realizados com derivados de SCUP, a exemplo da terapia do "StemCellEducator"(Educador de células estaminais), método onde há a coleta de uma pequena quantidade de sangue do paciente, passando o mesmo por um circuito fechado, que separa as células sanguíneas, expõe os linfócitos do paciente à CB-SC - células tronco multipotentes derivadas de SCUP, promovendo o "treinamento" dos mesmos e, após, devolvendo-os à circulação sanguínea do paciente. Esse tipo de tratamento possibilita reversão duradoura da autoimunidade ${ }^{(7)}$, melhora do controle metabólico em indivíduos com diabetes tipo ${ }^{\left({ }^{(8)}\right.}$, dentre outros.

Para transplante autólogo, o SCUP deve ser coletado no momento do nascimento do bebê, através de punção do cordão umbilical e placenta, sendo acondicionado em reservatório próprio para transporte até o laboratório do Banco de Sangue de Cordão Umbilical, onde será processado até que se obtenha o produto final para armazenamento(9)

Do momento da coleta até o processamento do SCUP, existem diversos fatores que podem influenciar na qualidade do mesmo, sendo os principais os fatores físicos (como temperatura) ${ }^{(10)}$, obstétricos (como características da placenta e cordão umbilical) ${ }^{(11,12)}$ neonatais (como peso e idade gestacional ao nascer) e operacionais (como práticas realizadas no manuseio da SCUP desde a coleta até o transporte e processamento) ${ }^{(13-15)}$.A qualidade, volume e celularidade (quantidade de células nucleadas totais)do produto final definirão se o mesmo pode ser classificado como viável para criopreservação ${ }^{10}$ (técnica de congelamento de tecidos vivos que utiliza substâncias conservantes e protetoras das células, de forma que as mesmas permaneçam viáveis após o descongelamento, com o mínimo de perda possível) ${ }^{(16)}$.

Existem critérios técnico-sanitários mínimos que os Laboratórios de processamento de células tronco pro- venientes de SCUP devem adotar para que seja permitido seu funcionamento e haja segurança e qualidade no método de processamento ${ }^{(10)}$. Os Bancos de Sangue de Cordão Umbilical e Placentário (BSCUP), baseados nesses regulamentos, formulam Protocolos Operacionais Padrão (POP) que determinam de que maneira o procedimento de coleta de SCUP deve ser realizado, visando tanto à qualidade do procedimento quanto ao atendimento aos requisitos especificados e o processamento de um produto ideal para o transplante. Se, além dos POP, os profissionais tivessem acesso também a um documento que reunisse informações acercados fatores que podem intervir na qualidade da USCUP, as repercussões poderiam ser positivas, já que, detentores dessas informações, combinadas, teriam a possibilidade de aperfeiçoar o procedimento.

Diante da problemática apresentada, o presente estudo tem como objeto os fatores que podem influenciar na qualidade do SCUP e tem como objetivos apontar os fatores que podem influenciar na qualidade da coleta de SCUP; definir os fatores que podem influenciar na qualidade da coleta de SCUP e analisar as boas práticas na coleta de SCUP, sintetizando, a seguir, informações fundamentais acerca de boas práticas de coleta.

\section{MÉTODOS}

Trata-se de um estudo de revisão integrativa, amplo procedimento metodológico que permite a inserção de pesquisas experimentais e não experimentais, assessorando a compreensão dos fatos avaliados através da combinação de dados de literatura teórica e empírica, tornando possíveis opções como revisão de teoria, definições de conceitos e análise de problemas a partir de assunto particular ${ }^{(17)}$.

A busca pelos artigos foi realizada no período de Maio a Julho de 20I8, baseada na metodologia PICO, um acrônimo para os termos"Paciente", "Intervenção", "Comparação" e "Outcome” (Resultado), que, por sua vez, fazem parte da questão de pesquisa ${ }^{(18)}$, tendo como pergunta formulada: "Para os profissionais coletadores de Sangue de Cordão Umbilical e Placentário (SCUPA), a elaboração de um protocolo relacionado aos fatores que interferem na qualidade do SCUPA poderia favorecer o aumento da qualidade dos materiais coletados, comparado a procedimentos baseados apenas nos POP dos BSCUPA?".

As buscas foram realizadas utilizando a Biblioteca Virtual de Saúde (BVS), plataforma quereune 14 bases de dados bibliográficas em ciências da saúde, que possuem artigos e documentos científicos, bem como bases referenciais como o Catálogo de Revistas Científicas e o DeCS. Os critérios de inclusão dos trabalhos foram: Publicações entre os anos 2008 e 2018 , disponibilizados na íntegra, disponibilizados gratuitamente, abordar o tema 
sangue de cordão umbilical e fatores de interferência da qualidade. Para critérios de exclusão: estudos realizados com animais; Teses e dissertações, estudos que promovam marcas ou empresas.

As buscas foram realizadas utilizando-se a associação dos seguintes descritores, através dos operadores booleanos "AND": "sangue de cordão umbilical", "protocolo clínico", "coletadores" e "qualidade”. Também foi utilizado vocabulárioMeSH controlado apropriado:"cordblood”,"quality”, "cordclamping”,"cordblood banking”, "fisicalfactors", "temperature”, "obstetricfactors","operationalfactors" e "placenta".

\section{RESULTADOS}

Foram analisados $265 \mathrm{I}$ artigos e após a aplicação dos critérios de inclusão e exclusão, foram selecionados 15 artigos:02 na língua portuguesa, 01 na língua espanhola e 12 na língua inglesa, ainda que os estudos sejam de outros países. O fluxograma abaixo apresenta detalhes da busca.
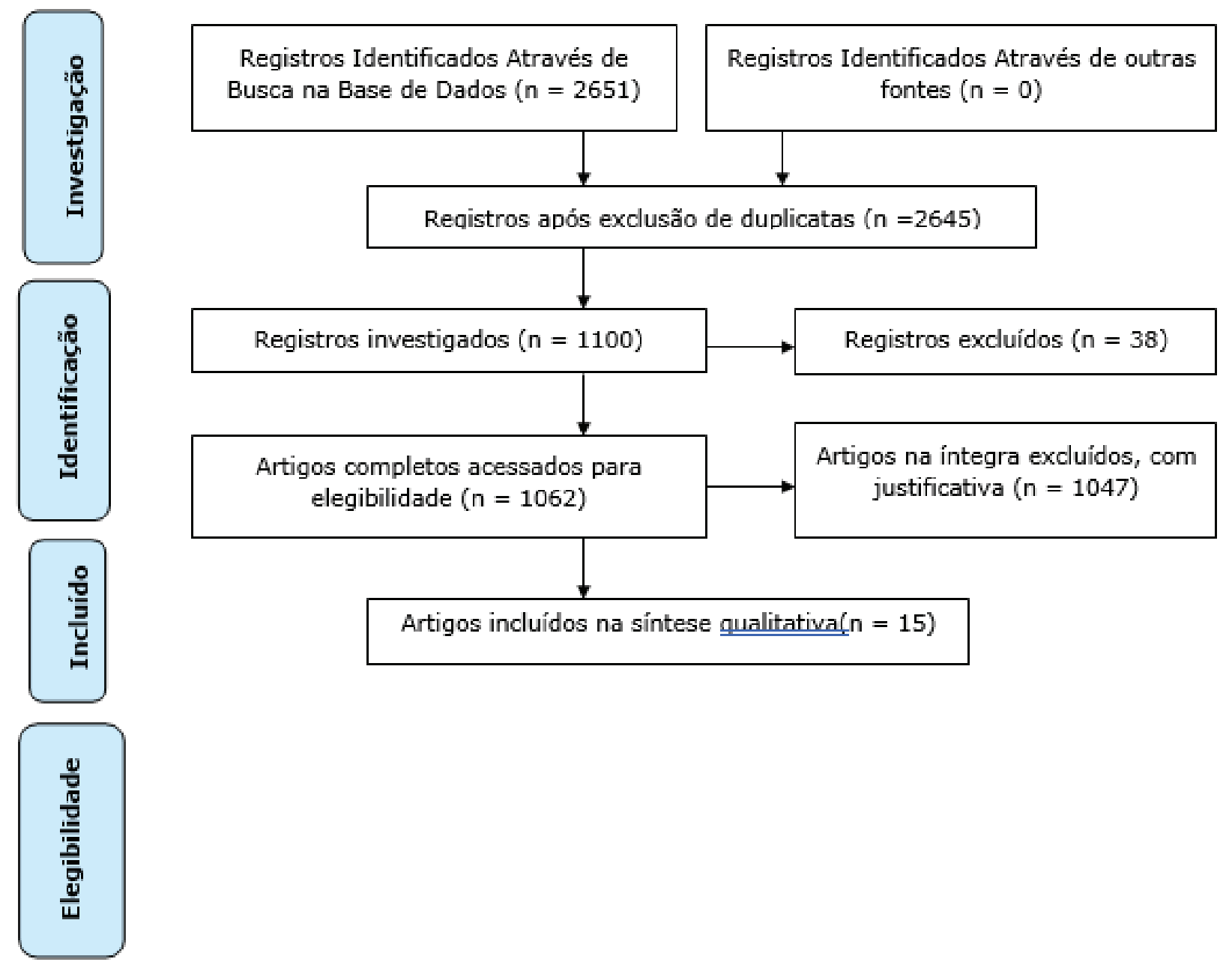

FLUXOGRAMA Prisma

\begin{tabular}{|c|c|c|c|c|}
\hline Título do Artigo & Autores & Periódico/Ano & Objetivo & Resultados \\
\hline $\begin{array}{c}\text { Boas práticas para a coleta } \\
\text { de sangue de cordão } \\
\text { umbilical e placentário }\end{array}$ & $\begin{array}{c}\text { Lopes LA, } \\
\text { Bernardino } \\
\text { E, Crozeta K, } \\
\text { Guimarães PRB. }\end{array}$ & $\begin{array}{l}\text { Rev. Latino-Am. } \\
\text { Enfermagem/2016 }\end{array}$ & $\begin{array}{l}\text { Identificar fatores relacionados à } \\
\text { qualidade das amostras do sangue } \\
\text { de cordão umbilical e placentário e } \\
\text { definir boas práticas para sua coleta } \\
\text { em um banco público de sangue de } \\
\text { cordão umbilical e placentário. }\end{array}$ & $\begin{array}{l}\text { Houve correlação na influência dos } \\
\text { fatores obstétricos e neonatais em } \\
\text { menor escala quando comparados aos } \\
\text { fatores operacionais, resultando na } \\
\text { necessidade de readequar a prática } \\
\text { profissional do coletador enfermeiro } \\
\text { e da equipe obstétrica envolvida no } \\
\text { processo da coleta de SCUP. }\end{array}$ \\
\hline $\begin{array}{l}\text { Correlación entre } \\
\text { características físicas } \\
\text { neonatales y maternas com } \\
\text { El recuento total de células } \\
\text { nucleadas y de células } \\
\text { CD34+ por microlitro em } \\
\text { sangre de cordón umbilical. }\end{array}$ & $\begin{array}{l}\text { Ordóñez FR, } \\
\text { Riaño DP, Martín } \\
\text { AL, Zárate AM, } \\
\text { Ávila, AR, Villamil } \\
\text { CAF, et al. }\end{array}$ & $\begin{array}{l}\text { rev.fac.med, Bogotá/ } \\
\qquad \begin{array}{c}2015 \\
2015\end{array}\end{array}$ & $\begin{array}{l}\text { Correlacionar variáveis maternas } \\
\text { e neonatais com a contagem total } \\
\text { de células nucleadas e CD34 +, } \\
\text { medidas em } \mu \mathrm{L} \text { (microlitro). }\end{array}$ & $\begin{array}{l}\text { Há correlação entre o comprimento } \\
\text { do cordão umbilical e a contagem de } \\
\text { células nucleadas,o total de células } \\
\text { nucleadas com o volume inicial e } \\
\text { contagem de células CD34 + em } \mu \mathrm{L} \text { e } \\
\mathrm{mL} \text { foi encontrada. }\end{array}$ \\
\hline
\end{tabular}




\begin{tabular}{|c|c|c|c|c|}
\hline $\begin{array}{l}\text { O intervalo de tempo entre } \\
\text { coleta e processamento do } \\
\text { sangue de cordão umbilical } \\
\text { influencia na qualidade da } \\
\text { amostra? }\end{array}$ & $\begin{array}{l}\text { Barini R, Ferraz } \\
\text { UC, Acácio GL, } \\
\text { Machado IN. }\end{array}$ & Einstein/ 2011 & $\begin{array}{c}\text { Avaliar a associação entre o tempo } \\
\text { desde a coleta do sangue do cordão } \\
\text { umbilical até o processamento e a } \\
\text { qualidade da amostra. }\end{array}$ & $\begin{array}{l}\text { As células nucleadas, células viáveis e } \\
\text { CD34 + diminuíram muito pelo aumento } \\
\text { do tempo entre amostragem e análise, } \\
\text { sendo a diferença entre } 24 \text { e } 48 \mathrm{~h} \\
\text { menor que a diferença entre } 24 \text { e } 72 \mathrm{~h} \text {. }\end{array}$ \\
\hline $\begin{array}{l}\text { Quality rather than quantity: } \\
\text { the cord blood bank dilemma }\end{array}$ & $\begin{array}{l}\text { Querol S, Gomez } \\
\text { S G, Paugliuca A, } \\
\text { Torrabadella M, } \\
\text { Madrigal JA }\end{array}$ & $\begin{array}{c}\text { Bone Marrow } \\
\text { Transplantation/2010 }\end{array}$ & $\begin{array}{l}\text { Determinar etapas críticas do } \\
\text { processo do SCUP que podem afetar } \\
\text { a viabilidade celular final; discutir } \\
\text { testes de liberação que asseguram } \\
\text { que a unidade é adequada. }\end{array}$ & $\begin{array}{l}\text { A manipulação extensiva somada a } \\
\text { fatores tais como tempo de trânsito, } \\
\text { temperatura de armazenamento } \\
\text { e composição celular resulta em } \\
\text { problemas de viabilidade. }\end{array}$ \\
\hline $\begin{array}{l}\text { Optimizing Donor Selection } \\
\text { for Public Cord Blood } \\
\text { Banking: Influence of } \\
\text { Maternal, Infant and } \\
\text { Collection Characteristics on } \\
\text { Cord Blood Unit Quality. }\end{array}$ & $\begin{array}{c}\text { Page KM, } \\
\text { Mendizabal A, } \\
\text { Staleinb B, Wease } \\
\text { S, Shoulars K, } \\
\text { Gentry T et al. }\end{array}$ & Transfusion/2014 & $\begin{array}{l}\text { Descrever as características que } \\
\text { identificam CBU de alta qualidade, } \\
\text { que podem ser usadas para informar } \\
\text { estratégias de coleta de CBU para } \\
\text { bancos públicos. }\end{array}$ & $\begin{array}{l}\text { Os CBU demais alta qualidade são } \\
\text { os com maiores níveis de TNCC } \\
\text { e CD34 + + UFC. Maior conteúdo } \\
\text { de CD } 34^{+} \text {ou CFU foram associados } \\
\text { a menor intervalo da coleta ao } \\
\text { processamento,idade gestacional } \\
\text { menor; raça caucasiana,maior peso do } \\
\text { RNe maior volume coletado. }\end{array}$ \\
\hline $\begin{array}{l}\text { Effects of obstetric factors } \\
\text { and storage temperatures on } \\
\text { the yield of endothelial colony } \\
\text { forming cells from umbilical } \\
\text { cord blood. }\end{array}$ & $\begin{array}{l}\text { Coldwell KE, Lee } \\
\text { SJ, Kean J, Khoo } \\
\text { CP, Tsaknakis JS, } \\
\text { Smythe J et al. }\end{array}$ & Angiogenesis/2011 & $\begin{array}{l}\text { Examinar possíveis critérios de } \\
\text { seleção obstétrica para alcançar } \\
\text { maior rendimento de ECFC das } \\
\text { UCB, e determinar se a temperatura } \\
\text { de armazenamento de UCB } \\
\text { e criopreservação afetaram o } \\
\text { rendimento e função do ECFC. }\end{array}$ & $\begin{array}{l}\text { O peso placentário foi o único fator } \\
\text { obstétrico estatisticamente significativo } \\
\text { que predisse a frequência de ECFC na } \\
\text { SCU. O armazenamento temporário de } \\
\text { UCB fresco a } 4{ }^{\circ} \mathrm{C} \text { reduziu o rendimento } \\
\text { de ECFC em comparação com o a } 22 \\
{ }^{\circ} \mathrm{C} \text {. A criopreservação de MNCs UCB } \\
\text { reduziu as recuperações de ECFC. }\end{array}$ \\
\hline $\begin{array}{l}\text { A new strategy for umbilical } \\
\text { cord blood collection } \\
\text { developed at the first } \\
\text { Colombian public cord } \\
\text { blood bank increases total } \\
\text { nucleated cell content. }\end{array}$ & $\begin{array}{l}\text { Vanegas D, } \\
\text { Triviño L, Galindo } \\
\text { C, Franco L, } \\
\text { Salguero G, } \\
\text { Camacho B, et al. }\end{array}$ & Transfusion/2017 & $\begin{array}{c}\text { Analisar dados do banco público } \\
\text { colombiano da UCB (Col CBB), } \\
\text { incluindo variáveis que afetam o } \\
\text { volume de sangue e as contagens } \\
\text { de TNC. }\end{array}$ & $\begin{array}{l}\text { Há correlação entre peso ao nascer } \\
\text { neonatal e celularidade. O novo método } \\
\text { de coleta aumentou a celularidade } \\
\text { em cerca de } 26 \% \text { e não alterou a } \\
\text { pré-criopreservação e recuperação, } \\
\text { viabilidade ou capacidade clonogênica } \\
\text { pós-descongelamento. Além disso, } \\
\text { mostrou uma taxa de contaminação } \\
\text { microbiana notavelmente baixa. }\end{array}$ \\
\hline $\begin{array}{l}\text { Maternal obesity associated } \\
\text { with increase in natural killer } \\
T \text { cells and CD8+ regulatory } \\
T \text { cells in cord blood units. }\end{array}$ & $\begin{array}{l}\text { Espinosa LOG, } \\
\text { Cervantes } \\
\text { LAM, Márquez } \\
\text { AM, Juárez KP, } \\
\text { Maldonado ER, } \\
\text { Ojeda JV. }\end{array}$ & Transfusion/2016 & $\begin{array}{l}\text { Determinar se fatores obstétricos, } \\
\text { maternos e fetais modificam o } \\
\text { número de subconjuntos de linfócitos } \\
\text { nas unidades da UCB. }\end{array}$ & $\begin{array}{c}\text { Número médio de células CD34 + foi } \\
\text { de } 4,45 \times 10^{6}, \text { célulasTreg NKT, CD3 } \\
+, \text { CD4 +, CD8 + e CD8 + CD25 + } \\
\text { FoxP3 + foi muito maior em mães com } \\
\text { sobrepeso ou obesas e células CD34 + } \\
\text { diminuídas. O número de células iNKT } \\
\text { e CD34 + diminuiu em Recém nascidos } \\
\text { de maior peso. }\end{array}$ \\
\hline $\begin{array}{l}\text { Pre-birth selection of } \\
\text { umbilical cord blood donors. }\end{array}$ & $\begin{array}{l}\text { Urcioli P, Passeri } \\
\text { S, Ceccarelli } \\
\text { F, Luchetti B, } \\
\text { Paolicchi A, Lapi } \\
\quad \text { S, et al.. }\end{array}$ & $\begin{array}{c}\text { Blood } \\
\text { Transfusion/2010 }\end{array}$ & $\begin{array}{l}\text { Fornecer base para seleção de } \\
\text { doadores de SCUP que forneceriam } \\
\text { CBU com volume suficiente e } \\
\text { contagem de glóbulos brancos, } \\
\text { reduzindo custos de coleta, } \\
\text { transferência e armazenamento. } \\
\text { Analisar CBU para ser inadequado } \\
\text { para transplante. }\end{array}$ & $\begin{array}{l}\text { A média de peso ao nascer dos recém } \\
\text { nascidos doadores foi de } 3484 \pm 389 \\
\text { gramas e a média de idade gestacional } \\
\text { foi de } 40 \pm 1 \text { semanas. Parâmetros } \\
\text { fisiológicos dos recém nascidos doadores } \\
\text { são apresentados na Tabela I. O volume } \\
\text { médio do CBU foi de } 118,2 \pm 21,8 \mathrm{~mL} \text { e o } \\
\text { conteúdo médio de células totais nucleadas } \\
\text { (TNC) do CBU foi de } 1,51 \times 10^{\circ} \text {. }\end{array}$ \\
\hline $\begin{array}{c}\text { Umbilical Cord Blood: } \\
\text { Counselling, Collection, and } \\
\text { Banking }\end{array}$ & $\begin{array}{l}\text { Armson B A, Allan } \\
\text { D S, Casper R F. }\end{array}$ & $\begin{array}{l}\text { J ObstetGynaecol- } \\
\text { Can/2015 }\end{array}$ & $\begin{array}{l}\text { Revisão sobre aconselhamento, } \\
\text { coleta, serviços de BSCUP, } \\
\text { diretrizes para profissionais } \\
\text { de saúde sobre educação do } \\
\text { paciente, consentimento, aspectos } \\
\text { processuais e opções para o BSCUP } \\
\text { no Canadá. }\end{array}$ & $\begin{array}{l}\text { Aconselhamento, coleta e serviços } \\
\text { de BSCUP, educação de profissionais } \\
\text { de saúde, indicações para coleta de } \\
\text { SCUP, risco e benefícios de curto e } \\
\text { longo prazo, morbidade materna e } \\
\text { perinatal, satisfação dos pais e custos } \\
\text { de assistência médica. }\end{array}$ \\
\hline $\begin{array}{l}\text { Time related variations } \\
\text { in stem cell harvesting of } \\
\text { umbilical cord blood. }\end{array}$ & $\begin{array}{l}\text { Mazzoccoli G, } \\
\text { Miscio G, Fontana } \\
\text { A, Copetti M, } \\
\text { Francavilla M, } \\
\text { Bosi A, Perfetto } \\
\text { F, et al. }\end{array}$ & $\begin{array}{l}\text { ScientificRe- } \\
\text { ports/2016 }\end{array}$ & $\begin{array}{l}\text { Avaliar as variações relacionadas } \\
\text { ao tempo do volume de sangue do } \\
\text { cordão umbilical (CTB), conteúdo } \\
\text { de células TNC e CD34 + de UCB } \\
\text { em relação aos fatores obstétricos, } \\
\text { neonatais e de coleta que } \\
\text { influenciam o volume e o conteúdo } \\
\text { de células hematopoiéticas de CBU. }\end{array}$ & $\begin{array}{c}\text { A imensão temporal influencia volde } \\
\text { SCUP e n }{ }^{\circ} \text { de células TNC e CD34+. } \\
\text { VoldeSCUPe TNC foram associados } \\
\text { a: ano de nascimento, idade } \\
\text { gestacional, via de parto, sexo/ peso } \\
\text { do RN.N }{ }^{\circ} \text { de CD34 + foi associado a: } \\
\text { ano, mês, hora do nascimento, Idade } \\
\text { gestacional, peso do RN, CBV, TNC, } \\
\text { CD34 + negativamente relacionados } \\
\text { com índice de Apgar aos } 1 \text { e } 5 \text { min. }\end{array}$ \\
\hline
\end{tabular}




\begin{tabular}{|c|c|c|c|c|}
\hline $\begin{array}{l}\text { Factor predicting total } \\
\text { nucleated cell counts in cord } \\
\text { blood units }\end{array}$ & $\begin{array}{l}\text { Al-Qahtani R, } \\
\text { Al-Hedythi S, Arab } \\
\text { S, Al-Juhani A, } \\
\text { Jawdat D. }\end{array}$ & Transfusion/2016 & $\begin{array}{c}\text { Para otimizar o uso clínico de } \\
\text { células-tronco em nossa população, } \\
\text { este estudo visa abordar diversas } \\
\text { variáveis que afetam a contagem } \\
\text { de TNC. }\end{array}$ & $\begin{array}{l}\text { Das } 16 \text { variáveis maternas e infantis } \\
\text { avaliadas, três fatores demonstraram } \\
\text { valor preditivo estatisticamente } \\
\text { significativo para o nível de TNC } \\
\text { aceito. O volume do CBU foi o melhor } \\
\text { fator preditivo, seguido do peso ao } \\
\text { nascer do RN e a via de parto. }\end{array}$ \\
\hline $\begin{array}{l}\text { Optimizing cord blood } \\
\text { collections: Assessing the } \\
\text { role of maternal and neonatal } \\
\text { factors. }\end{array}$ & $\begin{array}{c}\text { Philip J, } \\
\text { Kushwaha N, } \\
\text { Chatteerjee T } \\
\text { \&Mallhi R S. }\end{array}$ & $\begin{array}{l}\text { Asian Journal } \\
\text { of Transfusion } \\
\text { Science/2015 }\end{array}$ & $\begin{array}{c}\text { Determinar os fatores maternos e } \\
\text { neonatais que afetam as contagens } \\
\text { de células TNC e CD34 + no sangue } \\
\text { do cordão, de modo a auxiliar na } \\
\text { seleção adequada das unidades } \\
\text { de sangue do cordão para a } \\
\text { criopreservação }\end{array}$ & $\begin{array}{l}\text { O volume de SCU correlacionou-se } \\
\text { com rendimentos de células TNC, CD34 } \\
\text { + e CFU-GM. Placenta mais pesada e } \\
\text { bebê mais pesado foram associados } \\
\text { com um volume significativamente } \\
\text { maior de sangue de cordão, enquanto } \\
\text { a idade, a paridade da mãe e o sexo do } \\
\text { bebê não tiveram efeito significativo. }\end{array}$ \\
\hline $\begin{array}{l}\text { Four phases of checks for } \\
\text { exclusion of umbilical cord } \\
\text { blood donors. }\end{array}$ & $\begin{array}{l}\text { Volpe G, } \\
\text { Santodiroco M, Di } \\
\text { Mauro L, Miscio } \\
\text { G, Boscia FM, } \\
\text { Muto B, et al.. }\end{array}$ & $\begin{array}{c}\text { Blood } \\
\text { Transfusion/2011 }\end{array}$ & $\begin{array}{l}\text { Analisar a coleta do sangue do } \\
\text { cordão umbilical (SCU) em um ano } \\
\text { entre outubro de } 2008 \text { e setembro } \\
\text { de } 2009 \text {, buscando formas de } \\
\text { melhorar o número de unidades UCB } \\
\text { convenientes. }\end{array}$ & $\begin{array}{c}\text { O volume de SCU coletado após } \\
\text { cesárea foi maior que após o parto } \\
\text { vaginal. Após parto vaginal continham } \\
\text { um número maior de células nucleadas } \\
\text { totais que após a cesariana. }\end{array}$ \\
\hline $\begin{array}{l}\text { Optimizing umbilical cord } \\
\text { blood collection: impact } \\
\text { of obstetric factors versus } \\
\text { quality of cord blood units }\end{array}$ & $\begin{array}{l}\text { Mancinelli F, } \\
\text { Tamburini A, } \\
\text { Spagnoli A, } \\
\text { Malerba C, Suppo } \\
\text { G, lasorella R } \\
\text { et al. }\end{array}$ & $\begin{array}{l}\text { Transplant } \\
\text { Proc./2006 }\end{array}$ & $\begin{array}{l}\text { Determinar se os fatores obstétricos } \\
\text { influenciam as UCBs coletadas. }\end{array}$ & $\begin{array}{l}\text { Peso do RN foi principal fator para } \\
\text { o volume total, TNC, CD34,e CFU- } \\
\text { GM. Peso da placenta> } 600 \mathrm{~g} \text { teve } \\
\text { maior volume e } n^{\circ} \text { TNC.IG }>39 \\
\text { semanas aumentou CD } 34 \% \text { Cesárea } \\
\text { produziu> volume e }<n^{\circ} \text { leucócitos Sexo } \\
\text { feminino apresentou contagem de WBC } \\
\text { e CD34 (+) maior que o masculino. }\end{array}$ \\
\hline
\end{tabular}

$\mathrm{Na}$ análise dos estudos demonstrados acima, foram identificadasdiversas condições que interferem na qualidade da coleta de SCUP, que foram distribuídas em cinco itens. $O$ primeiro representa as características dos Fatores Obstétricos; o segundo, os Fatores Neonatais; o terceiro aborda os Fatores Maternos; o quarto, os Fatores Operacionais e o quinto, Fatores Físicos.

\section{Fatores obstétricos}

\section{a) Placenta}

Uma Pesquisa descritiva com abordagem quantitativa demonstrou que o peso placentário interfere na quantidade de células nucleadas e no volume de SCUP coletado, inferindo que quanto maior for o tamanho e peso desse órgão, maior será o volume coletado ${ }^{(20)}$.Esse manifesto foi reafirmadopor outros autores, que adicionam que, quanto maior o volume, maior a quantidade de células nucleadas obtidas da amostra ${ }^{(21-23)}$.

Um estudo com 365 USCUPA adiciona que há, ainda, correlação entre o peso da placenta e a quantidade de UFC (Células Formadoras de Colônias), também chamadas de células precursoras, no SCUP(24). Alguns autores adicionam que volume e celularidade melhoraram quando o peso da placenta foi entre que 600 e $700 \mathrm{~g}^{(25,22)}$.

Entretanto, há um estudo quenão encontrou relação entre o peso/tamanho da placenta e a quantidade de células nucleadas, mascorroborou com a afirmativa de que quanto maior for o volume coletado, maior será a celularidade obtida ${ }^{(26)}$.

\section{b) Cordão Umbilical}

Há informações acerca de características do cordão umbilical e de que forma pode-se associá-las ao volume coletado, chegando à conclusão de que quanto maior o calibre do cordão e mais cheio o mesmo for, maior o volume coletado e a celularidade da USCUPA ${ }^{(20,26)}$. Além disso, há relação entre o comprimento do cordão umbilical e o volume da amostra coletada, estabelecendo relação direta entreo comprimento do cordão, volume e, também, celularidade ${ }^{(26)}$. Há evidências de que o comprimento do cordão umbilical precisa ser igual ou maior que $30 \mathrm{~cm}$ para fornecer o volume de sangue adequado e que há aumento da celularidade e volume de SCUP coletados em cordões com comprimentos maiores de $55 \mathrm{~cm}^{(25,22)}$.

Existem também fatores associados à redução do volume sanguíneo do cordão umbilical, comoa hipertensão materna, tabagismo durante a gestação, gestação múltipla, parto prematuro, restrição de crescimento intra-uterino, placentação anormal, transferência materna ${ }^{(22)}$.

\section{Fatores Neonatais \\ a) Peso}

Há relatos de que o peso do recém-nascido está diretamente relacionado ao volume de SCUPA coletado e também à celularidade, e fortes correlações positivas entre a circunferência abdominal e o volume de SCUP, bem como o número de UFC, tendo sido encontrado melhores resultados em recém-nascidos com peso entre $3390 \mathrm{~g}$ e $3500 \mathrm{~g}^{(27,23,25,22,20,24)}$.

Há autores que relatem, ainda, que a cada $500 \mathrm{~g}$ a mais de peso de recém-nascido, há um aumento de $28 \%$ de células $\mathrm{CD}_{34}{ }^{+}$(fenótipo encontrado nas células tronco 
hematopoiéticas) e que a cada $500 \mathrm{~g}$ de desvio do peso médio do recém-nascido, houve uma chance $40 \%$ maior de produzir uma contagem de TNC que seria aceita para uso clínico ${ }^{(21,28)}$.

\section{b) Idade gestacional}

Bebês nascidos a termo apresentaram contagem celular significativamente maior em SCUP se comparados à bebês pré-termo. Além disso, foi encontrada uma correlação positiva (embora descrita como modesta) entre a celularidade obtida do SCUP coletado e a idade gestacional, obtendo melhores resultados em neonatos com idade gestacional de pelo menos 39 semanas $^{(23,22,25)}$.

Há relatos de que, com o advento do envelhecimento placentário, advindo do avanço da idade gestacional, pode ocorrer hipóxia fetal progressiva e um dos mecanismos de defesa do bebê seria o aumento das células hematopoiéticas e o volume sanguíneo circulante ${ }^{24}$.

Em contrapartida, outros referem que bebês de menor idade gestacional apresentaram menor contagem celular, entretanto maior contagem de CD34+(29,23).

\section{c) Etnia:}

Um estudo com 5267 SCUPAS avaliou que bebês caucasianos tendem a fornecer SCUPAS com maior potência (capacidade do SCUPA de passar por todas as fases do processamento com o mínimo de morte celular possível) e maior quantidade de UFC quando comparado a bebês afro-descendentes ${ }^{(29)}$.

\section{d) Sexo}

Com relação ao sexo, um dos estudos nega ter encontrado influência significativa, entretanto, admite que estudos anteriores divirjam nessa informação, ora correlacionando positivamente bebês do sexo masculino a amostras de maior volume, ora correlacionando positivamente bebês do sexo feminino ${ }^{(28)}$.

\section{e) Condições de estresse ao nascer}

É consenso entre alguns autores que situações que geram estresse e hipóxia neonatal no momento do parto, como trabalho de parto prolongado, índice de APGAR reduzido no $1^{\circ}$ e $5^{\circ}$ minutos, estão relacionadas ao aumento do volume e celularidade do $\operatorname{SCUP}^{(30,22)}$ e que em trabalhos de parto prolongados (o que gera estresse neonatal) e também o (baixo) $\mathrm{pH}$ sanguíneo do bebê influenciam positivamente no volume e celularidade do SCUP(25).

\section{Fatores maternos}

No contexto de obesidade materna, existe correlação entre a redução de células iNKT no fígado (células que reconhecem antígenos lipídicos e glicolipídicos) e seu aumento no tecido adiposo dos bebês. Isso funcionaria como um mecanismo compensatório, visto que essas células têm a capacidade de identificar e responder à alterações na homeostase de lipídios do tecido adiposo e então culminar no aumento do número de células
CD34+ em recém nascidos de menor peso $(<3000 \mathrm{~g})$ comparado a bebês de maior peso (em condições normais) ${ }^{(31)}$.

\section{Fatores Operacionais}

A forma descrita como sendo a melhor de se obter elevada celularidade em uma coleta é extrair o máximo de volume possível durante a punção do cordão umbilical e da placenta. Nesse contexto, podem ocorrer práticas indevidas que culminam na redução do volume coletado e, consequentemente, em menor celularidade do SCUP coletado $^{(20)}$. São elas:

\section{a) Tempo de clampeamento e corte incorreto do cordão}

Corte incorreto do cordão, deixando-o com menos de $30 \mathrm{~cm}$ (encontrado em 29,37\% das coletas ${ }^{(20)}$. Quanto ao tempo de clampeamento, estudos acerca das repercussões do clampeamento tardio e precoce do cordão umbilical na coleta de SCUP e seus achados revelaram que o clampeamento precoce do cordão (30 segundos após o parto) está diretamente relacionado a uma coleta com maiores volume e celularidade disponíveis no SCUP e, em contrapartida, quando ocorre o clampeamento tardio do cordão (I a 3 minutos após o parto) há a redução do volume de SCUP disponível para coleta ${ }^{(22)}$. Clampeamentos de cordão umbilical entre 30 e 60 segundos após o parto mostraram melhores números de celularidade ${ }^{(25)}$.

b) Manuseio incorreto da placenta

Exercer pressão elevada ao manusear a placenta foi um dos fatores que prejudicaram a integridade da mesma e ocorreu em $23,43 \%$ das coletas ${ }^{(20)}$;

\section{c) Ruptura ou laceração do cordão umbilical}

No período de expulsão da placenta, ao exercer pressão para auxiliar o processo, ocorreu ruptura ou leceração do cordão, prejudicando $21,60 \%$ das coletas ${ }^{(20)}$;

\section{d) Tempo entre a coleta e o proces- samento}

As amostras de SCUPA possuem maior taxa de células nucleadas quando processadas em até 24 horas após sua coleta. As amostras processadas em até 12 horas após a coleta apresentaram melhor rendimento final em laboratório, comparado às amostras processadas em 24 horas após a coleta, que horas tem perdas de células progenitoras e UFC significativas, se comparadas a amostras processadas em até 10 horas da coleta ${ }^{(20,29)}$.

Dados estatísticos acerca do intervalo entre a coleta e o processamento do SCUPA mostraramque amostras processadas em até 24 horas possuíam uma média de I,I bilhão de células nucleadas, enquanto que as amostras processadas em 48 horas apresentaram uma média de 967 milhões e as processadas em 72 horas apresentaram uma média de 7 II milhões de células nucleadas ${ }^{(13)}$. 
O percentual de celularidade inicial da amostra é inversamente proporcional ao tempo que se leva desde a coleta até $\circ$ processamento, sob o ponto de vista de que o material da bolsa de coleta é inadequado para o armazenamento do produto, em teoria. Essa hipótese é proveniente de uma reflexão baseada em um estudo que aponta que as bolsas de coleta foram confeccionadas em materialideal para o armazenamento de glóbulos vermelhos e que, quando outros tipos de células (o estudo em questão testou plaquetas) são armazenados na mesma, ocorre a morte celular progressiva com o passar das horas. Em teoria, ocorreria o mesmo com o SCUPA (sugere-se que em até 24 horas da coleta não há perda significativa de celularidade, mas o mesmo não pode ser afirmado após esse período) ${ }^{(32)}$.

\section{e) Tipo de coleta}

A técnica intra-útero (coleta realizada antes da dequitação/parto da placenta) produz volumes um pouco maiores de SCUP e maiores rendimentos de células nucleadas totais em comparação com a técnica extra útero (após a dequitação/parto da placenta) ${ }^{(22,11)}$ e estudos apontam que mesclar a coleta intra-útero com a coleta extra-útero há um aumento significativo do volume sanguíneo coletado, comparado às coletas intra-útero e extra-útero separadas.A técnica intra útero possui sucesso de $75 \%$ enquanto a extra útero possui $67 \%$. A coleta extra útero pode estar associada a menores volumes e celularidade devido ao fato de haver, após a dequitação, focos hemorrágicos e coágulos nas veias do cordão umbilical(27,25).

\section{f) Tipo de parto}

Após o parto cesáreo foi encontrado maior volume de SCUP para coleta, comparado ao parto vaginal $(95,4$ $\mathrm{mL}$ versus $85,0 \mathrm{~mL}$, respectivamente), mas foi na coleta após o parto vaginal que se obteve maior celularidade no $\operatorname{SCUP}\left(9,70 \times 10^{8}\right.$ células versus $8,74 \times 10^{8}$ células). Após o parto Cesário, houve redução de $40 \%$ da probabilidade de a celularidade ser satisfatória ${ }^{(25,28,29)}$.

\section{Fatores físicos}

\section{a) Temperatura}

O consenso sobre a temperatura ideal é de que quando armazenada entre 4 e $22^{\circ} \mathrm{C}$, em 24 horas, há pouca ou nenhuma influência na viabilidade celular ${ }^{21}$. Já as normas brasileiras vigentes preconizam que "o material permaneça à temperatura de $4{ }^{\circ} \mathrm{C}$ (mais ou menos $2^{\circ} \mathrm{C}$ )"

\section{Discussão}

É consenso entre os autores o entendimento de que o volume de SCUP coletado no momento do parto tem forte relação com a celularidade inicial da amostra ${ }^{20-}$ 27). Essa informação leva a crer que para que uma coleta seja bem-sucedida, o profissional responsável pela coleta deve, além de observar as normas que envolvem a coleta de SCUP e assegurar a qualidade do procedimento, co- letar o maior volume de SCUP possível, a fim de garantir uma amostra rica em células nucleadas que possa passar por todas as etapas do processamento e manter celularidade suficiente para ser elegível para armazenamento e transplante.

Além do volume de SCUP, outros fatores foram identificados como preponderantes para a qualidade e o sucesso de uma coleta. Algumas situações e procedimentos que envolvem a coleta que podem interferir na qualidade/quantidade da amostra. Para o aprimoramento técnico científico dos profissionais coletadores as informações consideradas mais relevantes foram recomendações de boas práticas que visam garantir uma coleta de qualidade e de maior volume e celularidade. Dentre elas observamos:

I. O tamanho do cordão umbilical é um fator que pode ser influenciado pelo profissional de obstetrícia e está diretamente ligado ao volume e celularidade do SCUP $(20,22,25,26)$. Assim, há de se destacar a importância do monitoramento e também da instrução da equipe obstétrica, pelo profissional coletador, durante o clampeamento e secção do cordão umbilical, para que se possa obter o maior tamanho de cordão (se possível, maior que $30 \mathrm{~cm}$ ).

2. A integridade do cordão umbilical e da placenta interfere significativamente no volume de SCUP disponível para coleta, já que, quando há laceração de um ou outro, há formação de coágulos e focos de hemorragia ${ }^{(25)}$. Mais uma vez, cabe orientação à equipe obstétrica. Quanto mais delicado for 0 manuseio do cordão durante a dequitação induzida da placenta, menores são as chances de trauma com prejuízo da integridade de ambos.

3. O tempo de clampeamento de cordão umbilical é foco de diversos estudos, sendo consenso entre alguns autores que há diversos benefícios para 0 bebê quando se aguarda de I a 3 minutos após o parto para efetuá-lo. Em contraste, outros autores evidenciam que o tempo ótimo de clampeamento de cordão após o parto, para obtenção de volume e celularidade satisfatórios em uma coleta de SCUP, seria entre 30 e 60 segundos ${ }^{(22)}$. Dessa maneira, apesar de não haver contraindicação para a coleta de SCUP após o clampeamento tardio do cordão, o ideal é orientar os pais do bebê antes do nascimento sobre as possíveis repercussões do clampeamento tardio do cordão na coleta de SCUP, bem como os benefícios do clampeamento tardio e deixar a decisão final a critério dos mesmos;

4. O intervalo de tempo de Processamento decorrido entre a coleta e o processamento provou-se relevante. $O$ entendimento dos autores quanto 
ao intervalo ótimo varia, mas todos sugerem que quanto menor for o intervalo, menor é a perda celular que ocorre durante o processamento ${ }^{(13,20,29)}$, sendo o limite máximo estabelecido pelas normas brasileiras de 48 horas $^{(10)}$;

5. O tipo de coleta foi dividido entre intra-útero e extra-útero. $\mathrm{O}$ primeiro foi descrito como sendo fonte de um maior volume coletado ${ }^{(22)}$. Mas um dos autores mencionou que a mescla das duas técnicas poderia ser causa de uma coleta ainda mais volumosa, se comparado às técnicas separadas ${ }^{(27)}$. Apenas um dos autores correlacionou a técnica intra-útero ao aumento de celularidade do SCUP

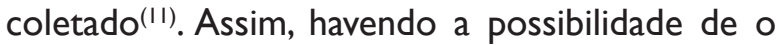
profissional coletador ser capacitado para realizar as duas técnicas simultaneamente ou, ainda, na impossibilidade de realiza-la, dar preferência à coleta intra-útero, a chance de obter-se uma amostra mais rica em volume e celularidade é maior;

6. A temperatura em que o SCUP é mantido entre a coleta e o processamento também se mostrou importante para a preservação e viabilidade das células $^{(10,21)}$.

Além dos fatores descritos acima, características maternas e neonatais que podem predizer o volume de uma amostra foram descritas por diversos autores. Essas características fogem ao controle dos profissionais coletadores, mas, por outro lado, quando existe a necessidade de selecionar apenas um bebê para realizar a coleta de SCUP (no caso de gemelares e apenas um coletador, por exemplo), tornam-se fundamentais na orientação do profissional. Nesse tipo de situação, o coletador deve se atentar para os seguintes aspectos:

I. Peso ao nascer: Foi consenso entre os autores que quanto mais pesado o bebê, maior será o volume de SCUP coletado. Assim, o coletador deve dar preferência para o bebê de maior tamanho, que aparente ter o maior peso(20,22-25,27);

2. Tamanho da Placenta: Assim como o peso do neonato, foi determinado que o tamanho e peso da placenta influenciam positivamente na quantidade de volume coletado, caracterizando uma placenta maior e mais pesada como a melhor opção de coleta(20-25);

3. Características do cordão umbilical: Um cordão umbilical maior, com mais fluxo, maior calibre e integridade melhor preservada, possui maior probabilidade de fornecer um volume adequado de sangue para coleta ${ }^{(20,22,25,26)}$;

4. Idade gestacional: Há controvérsias quando se trata de resultados relacionados à idade gestacional, mas a maioria dos autores refere que um bebê de maior idade gestacional tem maiores chances de fornecer mais volume e principalmente maior celularidade no SCUP(22-25).Assim, numa situação na qual há mais de um parto em andamento ou, ainda, numa gestação onde há bebês de idades gestacionais diferentes (quando ocorre mais de uma ovulação, com fecundação de ambos os óvulos, em tempos diferentes), é interessante que o coletador avalie outros aspectos antes de tomar a decisão.

5. Sexo/Etnia: Há muitas controvérsias relacionadas ao sexo do bebê e poucas informações acerca da etnia no que tange seu envolvimento com maior volume e celularidade de SCUP(29). Assim, não possuem a confiabilidade necessária para a tomada de decisão;

6. IMC materno: Existem evidências de que a obesidade materna durante a gestação altere de forma positiva o volume e celularidade de SCUP(3I). Um estudo realizado com 109 mães que apresentaram parto prematuro apontou que $42,20 \%$ dessas muIheres apresentaram sobrepeso e 32, I I\%, obesidade no final da gestação(33). Esses dados mostram uma relação significativa entre a obesidade e o parto prematuro e, por consequência, baixo peso neonatal. No contexto da coleta de SCUP, essa combinação de características poderia apontar para uma coleta de maior viabilidade, já que reúne três importantes fatores preditores de maior celularidade.

7. Tipo de Parto: A concordância entre os autores acerca do tipo de parto é que após o cesáreo há maior volume de SCUP disponível para coleta. Com relação ao parto vaginal, a coleta realizada após o mesmo apresenta maior celularidade (25, 28,29). Como já foi constatado no presente estudo que há correlação entre volume de SCUP e a celularidade, há necessidade de se exercer cautela no momento de fornecer orientações aos pais sobre o tipo de parto ideal para se coletar um SCUP de qualidade;

Foi descrito também, nesse estudo, que o trabalho de parto prolongado, baixo $\mathrm{pH}$ fetal, situações de estresse e hipóxia neonatal foram fatores preditores de maior celularidade no SCUP(22,24,25), entretanto, há de se avaliar sempre a possibilidade de haver comprometimento da segurança da mãe e do bebê nesses casos, o que constituiria forte contraindicação à coleta do SCUP.

Além disso, alguns autores abordaram uma proposta interessante: colocar o bebê no colo da mãe imediatamente após o nascimento. Essa ação, segundo seus estudos, beneficia não só o vínculo entre os dois, como também mostrou um aumento da quantidade de células CD34+ e do volume de recuperação do SCUP coletado(22,25). 
Outro fator de exímia importância a ser considerado é a implementação de educação continuada ao serviço, que proporciona ao profissional de saúde atualização técnicocientífica, consolidação das aptidões técnico-profissionais e melhora dos aspectos comunicativos entre equipe e família, fortalecendo, ainda, o comprometido com a vida do outro. Esse conjunto de características faz da Educação continuada um importante fator para se alcançar cuidados/procedimentos de saúde de qualidade ${ }^{(33)}$.

\section{CONCLUSÃO}

Em concordância com outros autores, esse estudo concluiu que para otimizar uma coleta, deve-se obter o maior volume possívelde SCUP, já que, dessa forma, a celularidade final estará aumentada. Para tal, existem características neonatais e maternas que podem ser observadas, procedimentos que podem ser aperfeiçoados e técnicas específicas que podem ser realizadas durante a coleta.

Assim, um serviço que ofereça acesso a um documento que reúna as informações pertinentes às boas práticas e qualidade da coleta e mantenha um programa de capacitação contínua dos profissionais coletadores e de obstetrícia acerca dos procedimentos adequados não só traria otimizaçãodas coletas e um serviço de maior qualidade, como também poderia evitar os principais erros que levam a uma coleta de baixa qualidade (volume/ celularidade) $)^{(20,22,34)}$.

Além disso, ao conhecer os fatores preditores de maior volume de SCUP, os profissionais teriam propriedade na tomada de decisão diante de partos múltiplos e ainda seriam capazes de orientar adequadamente os pais antes do nascimento do bebê. 


\section{REFERÊNCIAS}

I. Shufaro $Y$ \&Reubinoff B. Therapeutic applications of embryonic stem cells.Best Practice \& Research Clinical Obstetrics \& Gynaecology [internet].2004 [acesso em I5 mai 2018]; 18(6): 909-927. Disponível em: http://www.sciencedirect.com/science/article/pii/SI 52 I69340400 I22 I;

2. Kessinger A, Armitage JO, Landmarck JD, Smith DM,Weisenburger DD. Autologous peripheral hematopoietic stem cell transplantation restores hematopoieitc function following marrow ablative therapy. Blood [internet]. 1988 [acesso em I5 mai 2018]; 7I(3):723-727. Disponívelem: http://www.bloodjournal.org/content/bloodjournal/7//3/723.full.pdf;

3. Forrester LM, Bernstein A, Rossant J, Nagy A. Long-term reconstitution of the mouse hematopoietic system by embryonic stem cell-derived fetal liver. Proceedings of the $\mathrm{Na}$ tional Academy of Sciences of the United States of America [internet].199I [acesso em 15 mai 2018];88(I7):75I47517. Disponível em: http://www.pnas.org/content/ pnas/88/I7/75 I4.full.pdf;

4. Broxmeyer HE, Douglas GW, Hangoc G, Cooper S, Bard J, English D, et al. Human umbilical cord blood as a potential source of transplantable hematopoietic stem/progenitor cells. Proceedings of the National Academy of Sciences of the United States of America [internet]. 1989 [acesso em I5 mai 2018];86(I0):3828-3832. Disponível em: http:// www.pnas.org/content/pnas/86/I0/3828.full.pdf;

5. Hows JM, Marsh, JCW, Luft T, Coutinho L, Testa NG, Dexter TM, et al. Growth of human umbilical-cord blood in longtermhaemopoietic cultures. The Lancet [internet]. 1992 [acesso em I5 mai 2018];340:73-76.Disponível em: https://www.sciencedirect.com/science/article/pii /0I4067369290396K;

6. Mayani H; Rodríguez MG, Espinoza L, Chalini EL, Zepeda $\mathrm{AH}$, Flores E,et al. Kinetics of Hematopoiesis in DexterType Long-Term Cultures Established from Human Umbilical Cord Blood Cells. StemCells [internet]. 1988 [acesso em I5 mai 2018]; I6:127 - 135. Disponível em: https:// stemcellsjournals.onlinelibrary.wiley.com/doi/full/I0.1002/ stem.160127;

7. Zhao Y. Stem cell educator therapy and induction of immune balance. CurrDiab Rep [internet]. 2012[acesso em 22 mai 2018]; I 2:5 I 7-23. Disponível em: https://www.ncbi.nlm. nih.gov/pubmed/22833322;

8. Zhao Y, Jiang Z, Zhao T, Ye M, Hu C, Yin Z, et al. Reversal of type I diabetes via islet $\beta$ cell regeneration following immune modulation by cord blood-derived multipotent stem cells. BMC Medicine [internet]. 20I2[acesso em I5 mai 2018];10:3. Disponível em: https://www.ncbi.nlm.nih. gov/pmc/articles/PMC3322343/;

9. INCA. Instituto Nacional do Câncer. Instruções para coleta de Sangue de Cordão Umbilical e Placentário Doação Não-Aparentada. [internet] 2004 [acesso em 18 mai
2018]. Disponível em: http://www.inca.gov.br/publicacoes/ coleta_nao_aparentado_set_2004.pdf;

10. ANVISA. Agência Nacional de Vigilância Sanitária. Resolução da diretoria colegiada- RDC $n^{\circ} 56$, de 16 de Dezembro de 2010 [internet],[acesso em 15 mai 2018]. Disponível em: www.anvisa.gov.br/legis;

I I. Mancinelli F,Tamburini A,SpagnoliA,Malerba C,Suppo G,lasorellaR, et al. Optimizing umbilical cord blood collection: impact of obstetric factors versus quality of cord blood units.TransplantProc [internet].2006[acesso em 02 jun 20 I8];38(4):II74-6. Disponível em:http://www.sciencedirect.com/science/article/pii/S004 I I34506003472;

12. Keersmaekers C, Mason BA, Keersmaekers J, Ponzini M, Mlynarek RA. Factors affecting umbilical cord blood stem cell suitability for transplantation in an in utero collection program. Transfusion [internet].2014 [acesso em I5 mai 2018];54(3):545-549. Disponível em: http://onlinelibrary. wiley.com/doi/ I0. I I I I/trf. I2340/abstract;

I3. Barini R, Ferraz UC,Acácio GL, Machado IN. O intervalo de tempo entre coleta e processamento do sangue de cordão umbilical influencia na qualidade da amostra? Einstein [internet]. 20II [acesso em I5 mai 20I8];9(2):207-2 I I. Disponível em: http://www.scielo.br/pdf/eins/v9n2/pt_16794508-eins-9-2-0207.pdf;

14. Bertolini F,Lazzari L, Lauri E, Corsini C, Castelli C, Gorini Fet al. Comparative Study of Different Procedures for the Collection and Banking of Umbilical Cord Blood.Journal of Hematotherapy [internet]. 1995 [acesso em I 5 mai 2018];4(I):29-36. Disponívelem: http://online.liebertpub. com/doi/abs/I0.1089/scd.I.1995.4.29;

I5. Solves P, Moraga R, Saucedo E, Perales A, Soler MA, LarreaLet al. Cord blood stem cells Comparison between two strategies for umbilical cord blood collection Bone Marrow Transplantation [internet].2003 [acesso em 07 jun 20l8];3 I:269-273. Disponível em: https://www.nature. com/bmt/journal/v3 I/n4/pdf/ / 703809a.pdf;

16. Ribeiro RIMA,Godinho,HP.Criopreservação do sêmen testicular do teleósteo piau-açu Leporimusmacrocephalus.Arq. Bras. Med. Vet.Zootec [internet]. 2003 [acesso em 07 jun 20 I8];55: I Disponível em: http://www.scielo.br/scielo.php?script=sci_arttext\&pid=SO I 02=09352003000 I 000 I I-\&lng=en\&nrm=iso\&tlng$\mathrm{pt}$;

17. Souza MT, SilvaMD, Carvalho R. Revisão Integrativa: $O$ que é e como fazer. Einstein [internet]. 2010[acesso em 03 mai 2018]; 8:102-6. Disponível em:http://www.scielo.br/pdf/ eins/v8n I/pt_1679-4508-eins-8-I-0102.pdf;

18. Santos CMC, Pimenta CAM, Nobre MRC. The PICO strategy for the research question construction and evidence search. Rev. Latino-Am. Enfermagem [internet].2007 [acesso em 04 mai 2018];15(3): 508-5II. Disponível em: www. scielo.br/scielo.php?script=sci_arttext\&pid=SO I 04- I | 692007000300023\&Ing=en\&nrm=iso;

19. Moher D, Liberati A, Tetzlaff J, Altman DG. Principais 
itens para relatar Revisões Sistemáticas e Meta-análises: A recomendação PRISMA. Epidemiol. Serv. Saúde [internet]. 20I5[acesso em 07 jun 20I8];24(2). Disponível em: https://www.scielosp.org/pdf/ress/v24n2/2237-9622ress-24-02-00335.pdf;

20. Lopes LA, Bernardino E, Crozeta K, Guimarães PRB. Boas práticas para a coleta de sangue de cordão umbilical e placentário. Rev. Latino-Am. Enfermagem [internet], 2016 [acesso em I5 jun 2018];24:2770. Disponível em: www.scielo.br/scielo.php?script=sci_arttext\&pi$d=S 0104-$ I $1692016000100389 \&$ Ing=pt\&nrm=iso;

21. Coldwell KE, Lee SJ, Kean J, Khoo CP, Tsaknakis JS, Smythe J et al. Effects of obstetric factors and storage temperatures on the yield of endothelial colony forming cells from umbilical cord blood.Angiogenesis [internet].201 I [acesso em 22 jun 20I8];14(3):38I-392. Disponível em:www.ncbi.nlm.nih.gov/ pmc/articles/PMC3 I55043/pdf/I0456_20II_Article_9222.pdf;

22. Armson B A, Allan D S, Casper R F. Umbilical Cord Blood: Counselling, Collection, and Banking.J ObstetGynaecolCan [internet]. 2015 [acesso em 22 jun 20I8];37(9):832-844. Disponível em: https://www.jogc.com/article/SI70I2163(I5)30157-2/pdf;

23. Philip J, Kushwaha N, Chatteerjee T \&Mallhi R S. Optimizing cord blood collections:Assessing the role of maternal and neonatal factors. Asian Journal of Transfusion Science [internet]. 20I5[acesso em 22 jun 20I8]; 9(2):I63-167. Disponívelem: https://www.ncbi.nlm.nih.gov/pmc/articles/ PMC4562 I 38/?tool=pubmed;

24. Urcioli P, Passeri S, Ceccarelli F, Luchetti B, Paolicchi A, Lapi $S$, et al. Pre-birth selection of umbilical cord blood donors.Blood Transfusion [internet]. 2010[acesso em 22 jun 20I8];8(I):36-43. Disponível em:https://www.ncbi.nlm.nih. gov/pmc/articles/PMC28095 I0/pdf/blt-08-036.pdf;

25. Volpe G, Santodiroco M, Di Mauro L, Miscio G, Boscia FM, Muto B, et al. Four phases of checks for exclusion of umbilical cord blood donors. BloodTransfusion [internet]. 20 I I [acesso em 22 jun 20 I8];9(3):286-29I. Disponível em: https://www.ncbi.nlm.nih.gov/pmc/articles/PMC3।36596/ pdf/blt-09-286.pdf;

26. Ordóñez FR, Riaño DP, Martín AL, Zárate AM, Ávila, AR, Villamil CAF, et al.Correlación entre caraterísticas físicas neonatales y maternascon El recuento total de células nucleadas y de células CD34+ por microlitro em sangre de cordónumbilical. rev.fac.med, Bogotá [internet].
2015 [acesso em 22 jun 2018];23(2):7I-77. Disponível em: http://www.scielo.org.co/scielo.php?script=sci_arttext\&pid=SO I 2 I-525620 I $5000200008 \& \operatorname{lng}=$ en\&nrm=iso;

27. Vanegas D, Triviño L, Galindo C, Franco L, Salguero G, Camacho $B$, et al. A new strategy for umbilical cord blood collection developed at the first Colombian public cord blood bank increases total nucleated cell content. Transfusion [internet]. 2017[acesso em 0I jul 2018];57(9): 22252233. Disponível em: https://onlinelibrary.wiley.com/doi/ abs/10.1 I I I/trf.I4190;

28. Al-Qahtani R, Al-Hedythi S, Arab S, Al-Juhani A, Jawdat D. Factor predicting total nucleated cell counts in cord blood units. Transfusion [internet].2016[acesso em 0I jul 20I8];56:2352-2354. Disponível em: https://onlinelibrary. wiley.com/doi/epdf/ I0. I I I I/trf. I3707;

29. Page KM, Mendizabal A, Staleinb B, Wease S, Shoulars K, Gentry Tet al. Optimizing Donor Selection for Public Cord Blood Banking: Influence of Maternal, Infant and Collection Characteristics on Cord Blood Unit Quality. Transfusion [internet].20I4[acesso em 0 I jul 20 I8];54(2):340-352. Disponível em: https://www.ncbi.nlm.nih.gov/pmc/articles/PMC3766489/?tool=pubmed;

30. Mazzoccoli G, Miscio G, Fontana A, Copetti M, Francavilla $M$, Bosi $A$, Perfetto $F$, et al. Time related variations in stem cell harvesting of umbilical cord blood. ScientificReports [internet].2016[acesso em 0I jul 2018];6:2I404. Disponívelem: https://www.ncbi.nlm.nih.gov/pmc/articles/ PMC4764902/pdf/srep2 I404.pdf;

3I. Espinosa LOG, Cervantes LAM, Márquez AM, Juárez KP, Maldonado ER, Ojeda JV. Maternal obesity associated with increase in natural killer $T$ cells and $C D 8+$ regulatory $T$ cells in cord blood units. Transfusion [internet]. 2016[acesso em 01 jul 2018];56(5): I075-8.Disponívelem: https://onlinelibrary.wiley.com/doi/abs/10.1 I I I/trf. I348I;

32. QuerolS, Gomez S G, Paugliuca A, Torrabadella M, Madrigal JA. Quality rather than quantity: the cord blood bank dilemma. BoneMarrowTransplantation [internet]. 2010 [acesso em 0 l jul 2018];45:970-978. Disponível em: https:// www.nature.com/articles/bmt20107.pdf;

33. Teixeira GA, Carvalho JBL, Sena AV, Morais PC, Alves TRM. Características maternas de partos prematuros. Revista Enfermagem Atual [internet]. 2017 [acesso em 24 nov 2018]; 81: 19-23. Disponível em: https://revistaenfermagematual.com.br/uploads/revistas//9/02.pdf; 